\title{
Una invitación a repensar la enseñanza en radiología
}

\author{
Francisco Garrido C. ${ }^{1,2}$
}

1. Departamento de Radiología y Diagnóstico por Imágenes, Escuela de Medicina, Pontificia Universidad Católica de Chile. Santiago, Chile.

2. Centro de Educación Médica y Ciencias de la Salud, Facultad de Medicina, Pontificia Universidad Católica de Chile. Santiago, Chile.

Señor Editor:

La pandemia por el nuevo coronavirus (SARSCoV-2) ha modificado dramáticamente nuestra forma de trabajar, relacionarnos y comunicarnos, como consecuencia de la recomendación de distanciamiento social por parte de la autoridad, como una de las medidas para mitigar la propagación acelerada de la infección. Consecuencia de lo anterior se han implementado estrategias para resguardar la seguridad de los integrantes del equipo radiológico, como los turnos de trabajo "on-off", teletrabajo, restricción del flujo de personas por las dependencias de los servicios e interconsultas radiológicas por vía telefónica1.

El sistema educativo en todos sus niveles también se vio forzado a modificar sus prácticas, en un vertiginoso proceso de adaptación de la docencia hacia las plataformas digitales, en muchas ocasiones sin la preparación ni expertiz adecuada. Sin embargo, esta migración hacia una docencia mediada por tecnologías de la información y comunicación no puede ser considerada aún como una modalidad e-learning, ya que no ha habido tiempo para repensar la manera de enseñar y aprender, planificar el diseño instruccional y las estrategias de evaluación, y capacitar apropiadamente a la mayoría del cuerpo docente ${ }^{2}$. Mas bien es una "docencia de emergencia en línea" que ha permitido enfrentar rápidamente las demandas en estos tiempos de pandemia COVID-19, pero que no ha estado exenta de desafíos inherentes a su implementación, como la integridad académica, el respeto a la propiedad intelectual, la promoción del bienestar y autocuidado de los estudiantes, docentes y sus familias, o el acceso a recursos tecnológicos como computadores y conexión a Internet.

En lo que respecta a la educación superior, es probable que la formación de los profesionales de la salud haya sido la más afectada. Por un lado, el cierre de los campus universitarios ha impedido llevar a cabo nuestra tradicional docencia en aulas y laboratorios, y la suspensión de las rotaciones clínicas en todos sus niveles han obligado a los educadores médicos a pensar con flexibilidad y creatividad la continuidad de los programas de formación. No obstante, en el caso del sector sanitario, la atención directa de los pacientes afectados por la enfermedad impone un estrés mayor a quienes participan de una u otra manera en la educación universitaria.

La actividad docente en nuestros departamentos académicos de radiología también ha experimentado un cambio en este período. En relación a la docencia de pregrado, los internados, incluyendo las rotaciones por los servicios de imágenes, fueron suspendidos en gran parte del mundo con el propósito de prevenir el contagio de los internos y sus familias, o incluso redestinar las actividades prácticas de los estudiantes de cursos superiores al reforzamiento de los equipos sanitarios. En esta línea, existen en la literatura reciente interesantes iniciativas de diseño e implementación de rotaciones virtuales de radiología para internos, que incluyen metodologías de aprendizaje como la clase invertida, conferencias didácticas sincrónicas, discusión de grupos pequeños y revisión personal de material educativo disponible en la red o creado por los propios docentes. Los autores señalan que estas iniciativas han tenido una muy buena recepción por parte de los estudiantes y docentes, sin embargo, un aspecto por mejorar es que los internos no tienen la posibilidad de observar el rol del radiólogo en acción, uno de los objetivos de la rotación presencial ${ }^{3,4}$. No obstante, dadas sus características, es nuestra especialidad una de las áreas de formación de pregrado más susceptibles de adaptar a estos nuevos formatos, que seguramente serán la base de la docencia del futuro.

La docencia de aula migró a plataformas como Zoom, Meet o GoToMeeting, permitiendo así mantener la interacción entre estudiantes y docentes. En nuestra experiencia, los estudiantes han expresado 
su satisfacción con el módulo de radiología en este formato, entre otras razones, porque les permite visualizar directamente los casos en su computador y no en la pantalla de un aula de clases.

Al igual que en la educación de pregrado, la formación teórica de los residentes se ha efectuado a través de videoconferencias, con clases magistrales, revisiones de casos, journal clubs, entre otras. Además, muchas sociedades internaciones líderes en radiología generosamente han puesto a disposición de la comunidad radiológica mundial sus propios recursos educativos, incluyendo conferencias de congresos, artículos científicos o webinars. Las sesiones de informe de casos con residentes en la estación de trabajo revisten una especial importancia por ser la experiencia educativa más relevante durante la residencia y el centro de la docencia clínica radiológica, sin embargo, su realización efectiva está seriamente tensionada por el necesario distanciamiento físico. La adaptación creativa de las tecnologías, utilizando la teleradiología como estrategia docente, permitirá afrontar con éxito esta "nueva normalidad" en el proceso educativo ${ }^{5}$. Por otro lado, una de las amenazas en este tiempo de pandemia es que nuestros residentes no puedan cumplir con un número de exámenes que les permita lograr la competencia mínima esperada para un determinado nivel o rotación, considerando el escenario de disminución de exámenes imagenológicos. Ante este desafío, ya se reportan experiencias exitosas de simulación de reportes radiológicos como una estrategia metodológica para afrontar este desafío ${ }^{6}$.

Sin duda que muchos de estos cambios han llegado para quedarse en nuestro quehacer académico. A lo largo de la historia han sido crisis los gatillantes del cambio. Nuestra especialidad, ligada al desarrollo de tecnologías, la creatividad e innovación, tiene hoy una valiosa oportunidad para liderar una nueva forma de educar a las próximas generaciones de profesionales de salud.

\section{Referencias}

1. Alvin MD, George E, Deng F, Warhadpande S, Lee SI. The Impact of COVID-19 on Radiology Trainees. Radiology. 2020; 296(2): 246-248.

2. Seoane HA. The University in the Coronaceno (PostCOVID-19) Era. Educ Medica. 2020; 21(4): 221-222.

3. Durfee SM, Goldenson RP, Gill RR, Rincon SP, Flower E, Avery LL. Medical Student Education Roadblock due to COVID-19: Virtual Radiology Core Clerkship to the Rescue. Acad Radiol. 2020 Jul 24. (Epub ahead of print).

4. Gomez E, Azadi J, Magid D. Innovation Born in Isolation: Rapid Transformation of an In-Person Medical Student Radiology Elective to a Remote Learning Experience During the COVID-19 Pandemic. Acad Radiol. 2020 Jun 18. (Epub ahead of print).

5. Nadgir R. Teaching Remotely: Educating Radiology Trainees at the Workstation in the COVID-19 Era. Acad Radiol 2020 May 23. (Epub ahead of print).

6. Recht MP, Fefferman NR, Bittman ME, Dane B, Fritz J, Hoffmann JC, et al. Preserving Radiology Resident Education During the COVID-19 Pandemic: The Simulated Daily Readout. Acad Radiol. 2020; 27(8): 1154-1161. 